doso en la 1

ar ejemplos a

is funcionalidac uso, dependiende encarnan los conceptos detr por e $\Lambda$ influ
$\mathrm{Pe}$ infin:

Las formas $d r$ oceso de sig ialidad .

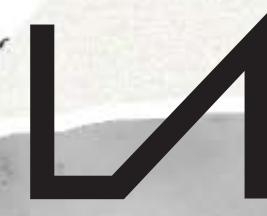

R E V I S A
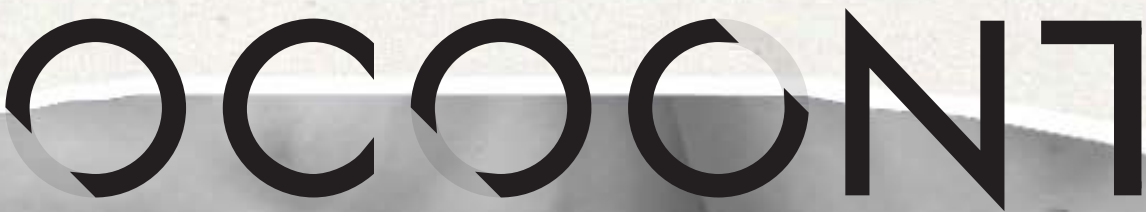

D $E$

No $6 \cdot 2019 \cdot$ ISSN 2386-8449

"El producto del diseñador es un proyecto, el estado previo de un objeto", Entrevista con Norberto Chaves, por Fernando Infante

El papel de la investigación y la teoría en diseño. Una conversación abierta, por Fernando Infante y María Jesús Godoy

UT PICTURA POESIS

Abandonar la escritura. Poesía experimental y manifiesta, Ignacio Gómez de Liaño

PANORAMA: FILOSOFÍA DEL DISEÑO Sección coordinada por Fernando Infante y María Jesús Godoy

Pensar el diseño, Fernando Infante y María Jesús Godoy (Coordinadores)

TEXTOS INVITADOS

Estatus y estado del điseño más allá del objeto, Pedro Medina Reinón

Mar de Nubes, Cuerpo de Cristal, Dionisio González

ARTÍCULOS

Understanding Design Aesthetics beyond Functional Beauty accounts, Lucía Jiménez Sánchez

Estética y diseño industrial: debates y controversias, Joan M. Marín

Del ornamento al delito. El diseño y la sociedad en Charles Baudelaire y Adolf Loos, Jorge López Lloret

When is Architecture not Design? Saul Fisher

Diseño y habitabilidad: una aproximación basada en los lenguajes de patrones, Antonio Hidalgo Pérez

Marcel Breuer: un diseñador global. Experiencias en el ámbito de la vivienda prefabricada, Salvador J. Sanchis, Ignacio Peris y Pedro Ponce Diseño y artes escénicas: el papel de Oskar Schlemmer en Das Triadische Ballett y la actualidad de la Bauhaus, Milagros García Vázquez Lo performativo en prácticas de arte y diseño actuales vinculadas a procesos de innovación social. El caso de La Venezia che non si vede y de La borda, Tània Costa Gomez

Articulaciones de la estética y el diseño. El caso de la evaluación a partir de la investigación dirigida en la carrera de diseño escénico de la Universidad de las Artes de Cuba, Mara Rodríguez Venegas y Xiomara Romero Rojas

SUPLEMENTO

El diseño, la ciudad y un lápiz de labios, Mercedes Espiau, Mar García Ranedo y Alejandro Rojas mas. 


\section{UつCつCNTE}

No $6 \cdot 2019 \cdot \operatorname{ISSN} 2386-8449 \cdot$ DOI 10.7203/LAOCOONTE.5.15381

https://ojs.uv.es/index.php/LAOCOONTE/index

COORDINACIÓN EDITORIAL

Anacleto Ferrer (Universitat de València)

Francesc Jesús Hernàndez i Dobon (Universitat de València)

Fernando Infante del Rosal (Universidad de Sevilla)

SECRETARÍA DE REDACCIÓN

Lurdes Valls Crespo (Universitat de València)

Vanessa Vidal Mayor (Universitat de València)

COMITÉ DE REDACCIÓN

Tamara Djermanović (Universitat Pompeu Fabra), Rosa Fernández Gómez (Universidad de Málaga), Anacleto Ferrer (Universitat de València), Ilia Galán (Universidad Carlos III), Ana María García Varas (Universidad de Zaragoza), María Jesús Godoy (Universidad de Sevilla), Fernando Infante del Rosal (Universidad de Sevilla), Miguel Ángel Rivero (Universidad de Sevilla), Miguel Salmerón (Universidad Autónoma de Madrid), Gerard Vilar (Universitat Autònoma de Barcelona).

COMITÉ CIENTÍFICO INTERNACIONAL

Rafael Argullol* (Universitat Pompeu Fabra), Luis Camnitzer (State University of New York), José Bragança de Miranda (Universidade Nova de Lisboa), Bruno Corà (Università di Cassino), Román de la Calle* (Universitat de València), Eberhard Geisler (Johannes Gutenberg-Universität Mainz), José Jiménez* (Universidad Autónoma de Madrid), Jacinto Lageira (Université Paris 1 Panthéon-Sorbonne), Bernard Marcadé (École Nationale Supérieure d'Arts de Paris-Cergy), Elena Oliveras (Universidad de Buenos Aires y Universidad del Salvador), Pablo Oyarzun (Universidad de Chile), Francisca Pérez Carreño* (Universidad de Murcia), Bernardo Pinto de Almeida (Faculdade de Belas Artes da Universidade do Porto), Luigi Russo (Università di Palermo), Georges Sebbag (Doctor en Filosofía e historiador del surrealismo), Zoltán Somhegyi (University of Sharjah, United Arab Emirates), Robert Wilkinson (Open University-Scotland), Martín Zubiria (Universidad Nacional de Cuyo). *Miembros de la Sociedad Española de Estética y Teoría de las Artes, SEyTA

\begin{tabular}{lll}
\hline DIRECCIÓN DE ARTE & REVISIÓN DE TEXTOS & TRANSCRIPCIÓN DE TEXTOS \\
El golpe. Cultura del entorno & Antonio Cuesta & Álvaro G. Serna
\end{tabular}

(cc) BY Excepto que se establezca de otra forma, el contenido de esta revista cuenta con una licencia Creative Commons Atribución 3.0 España, que puede consultarse en http://creativecommons.org/licenses/by/3.0/es/deed.es

EDITA

\section{SEyTA.}

CON LA COLABORACIÓN DE

\begin{tabular}{|c|c|c|c|}
\hline $\begin{array}{l}\text { VNIVERSITAT } \\
\text { B VALENCIA } \\
\text { Institut te Creativitat } \\
\text { | |nnovacions Educatives }\end{array}$ & $\begin{array}{l}\text { VNIVERSITAT } \\
\text { IE ÖVALENCIA Departament de Filosofia }\end{array}$ & 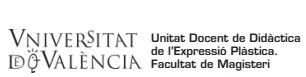 & \\
\hline $\begin{array}{l}\text { DEPARTAMENTO DE ESTÉTICA } \\
\text { E HISTORIA DE LA FLLOSOFIA }\end{array}$ & $\frac{\text { UAW }}{\frac{\text { UNIVRSSIDAD AUTONOMA }}{\text { DE MADRID }}}$ & $\begin{array}{l}\text { Universitat Autònoma } \\
\text { de Barcelona }\end{array}$ & $\begin{array}{l}\text { VNiVERSiDAD } \\
\text { Departamento de Filosofia, Lógica y Estética }\end{array}$ \\
\hline
\end{tabular}

LAOCOONTE aparece en los catálogos: 


\section{LつCつCN7E}

"Cuanto más penetramos en una obra de arte más pensamientos suscita ella en nosotros, y cuantos más pensamientos suscite tanto más debemos creer que estamos penetrando en ella".

G. E. Lessing, Laocoonte o los límites entre la pintura y la poesía, 1766.

Vo hay cól.

létodo, de pen.

:ión en general. Ith

zar la forma para el $\mathrm{n}$.

eptual por las orígenes

la, el objeto, la exposición

storia, porque existe en el $\mathrm{m}$

das sus raíces. Desde alli cc _. panoram

n conceptual y donde el émencia del con 'iseñado, como es el a al objeto y el di $\begin{array}{ll}\text { igen } \mathrm{de}^{\text {to }} \text { la inmer } & \text { tolvidada, o comc } \\ \text { trozo de madera ar }\end{array}$ a manera dorm comunicar ene nundo. Seguin? sngo en manos te el método $C$ les. A partir c teria prima $\mathrm{p}_{\mathbf{c}}$

'xto se puede:

¿ño, en proyea

amientos de $\mathrm{u}$

a conscie-

.)

en la publicación jue "plos de la impor te las nalidades porqu ura un ${ }^{2}$ diendo de qui zenerar $\mathrm{u}$ ción de nr? lne

in-

n-

is.

le http:,

le crear visualidades. A partir de.

ellas la propia materia prima para un en que desde un texto se puede generar $u_{11}$ i

Pensar en diseño, en proyección de nue

posibles comportamientos de una colecti

presente como una consciencia del hecho que estamos elaborando, significac

nuestro entorno (..)

Cardoso, R. C. Rafael. (2014). Design para um mundo complexo. Sãc asil: Cosac Naify. 


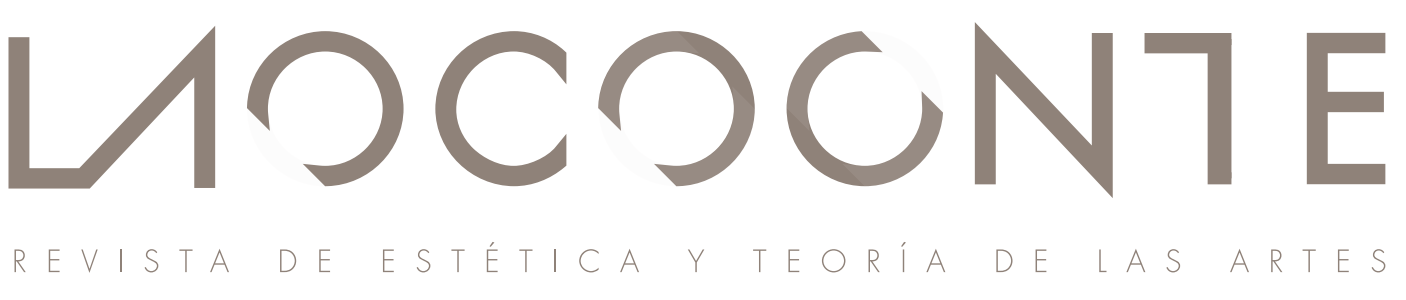

$\mathrm{N}^{\circ} 6 \cdot 2019$

PRESENTACIÓN

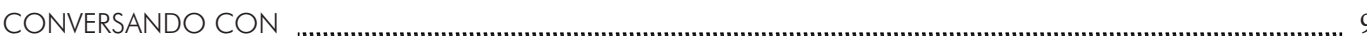

"El producto del diseñador es un proyecto, el estado previo de un objeto", Entrevista con Norberto Chaves,

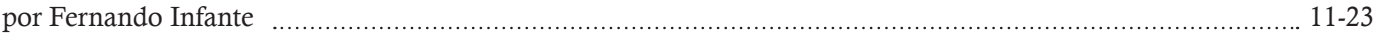

El papel de la investigación y la teoría en diseño. Una conversación abierta, por Fernando Infante

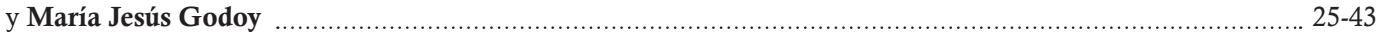

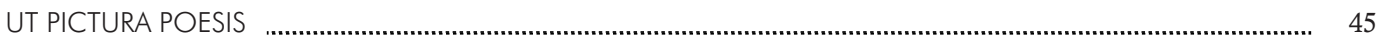

Abandonar la escritura. Poesía experimental y manifiesta, Ignacio Gómez de Liaño ................................................ 47-95

Imágenes de Laocoonte n. 6, de Isadora Gonzaga ................................................................................................... 96-97

PANORAMA

FILOSOFÍA DEL DISEÑO

Pensar el diseño, Fernando Infante y María Jesús Godoy (Coordinadores) .............................................. 101-105

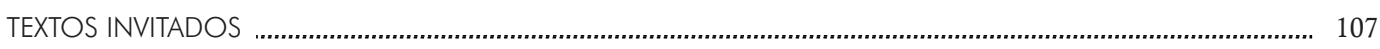

Estatus y estado del diseño más allá del objeto, Pedro Medina Reinón . ................................................... 109-125

Mar de Nubes. Cuerpo de Cristal, Dionisio González .............................................................................. 127-133

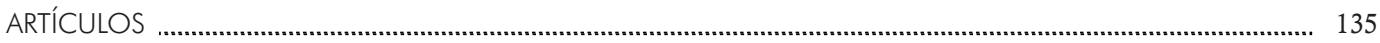

Understanding Design Aesthetics beyond Functional Beauty accounts, Lucía Jiménez Sánchez ................. 137-149

Estética y diseño industrial: debates y controversias, Joan M. Marín _...................................................... 150-164

Del ornamento al delito. El diseño y la sociedad en Charles Baudelaire y Adolf Loos, Jorge López Lloret ... $165-182$

When is Architecture not Design? Saul Fisher ……............................................................................. 183-198

Diseño y habitabilidad: una aproximación basada en los lenguajes de patrones, Antonio Hidalgo Pérez ...... 199-215

Marcel Breuer: un diseñador global. Experiencias en el ámbito de la vivienda prefabricada,

Salvador José Sanchis, Ignacio Peris y Pedro Ponce

Diseño y artes escénicas: el papel de Oskar Schlemmer en Das Triadische Ballett y la actualidad de la Bauhaus, Milagros García Vázquez

Lo performativo en prácticas de arte y diseño actuales vinculadas a procesos de innovación social.

El caso de La Venezia che non si vede y de La borda, Tània Costa Gomez

Articulaciones de la estética y el diseño. El caso de la evaluación a partir de la investigación dirigida en la carrera de diseño escénico de la Universidad de las Artes de Cuba, Mara Rodríguez Venegas

y Xiomara Romero Rojas

SUPLEMENTO 
Walter Gropius. La vida del fundador de la Bauhaus, Jorge Martínez Alcaide

¿Qué significa pensar la política desde la estética? Àger Pérez Casanovas

Ideologías estéticas en los orígenes de la pintura moderna, José Luis Plaza Chillón 300-303

Sobre a estética, Luis Carlos Pereira

Músicas populares. Sociedad y territorio: Sinergias entre investigación y docencia, Mar Aleixandre Badenes.

307-309

La necesidad de la mirada antropológica sobre la literatura, Pablo de Benito David

A propósito de Chandler, o la novela policíaca como tratado filosófico, Juan Evaristo Valls Boix

Videre aude!, Anacleto Ferrer

La inaplazable memoria del dolor y el sufrimiento, Antonio Notario Ruiz

La alargada sombra de la pintura, Raquel Baixauli

Sondear la maravilla, Juan Evaristo Valls Boix

... Y lo sabes, Marc Hernández Montoro

Arqueologías de la modernidad en las artes. Ensayo estético, Carlota Fernández-Jáuregui Rojas

Estética de la Instalación, Luis Cemillán Casis

La Herencia de otra época, María Jesús Godoy Domínguez

Del Theatrum Mundi al Gran Vidrio, Miguel Salmerón Infante

Imágenes de Isadora Gonzaga.

Fotografía de portada de Tamara Djermanovic intervenida por Isadora Gonzaga.

Los coordinadores de la sección Panorama: Filosofia del diseño agradecen

a Antonio Molina Flores su colaboración. 


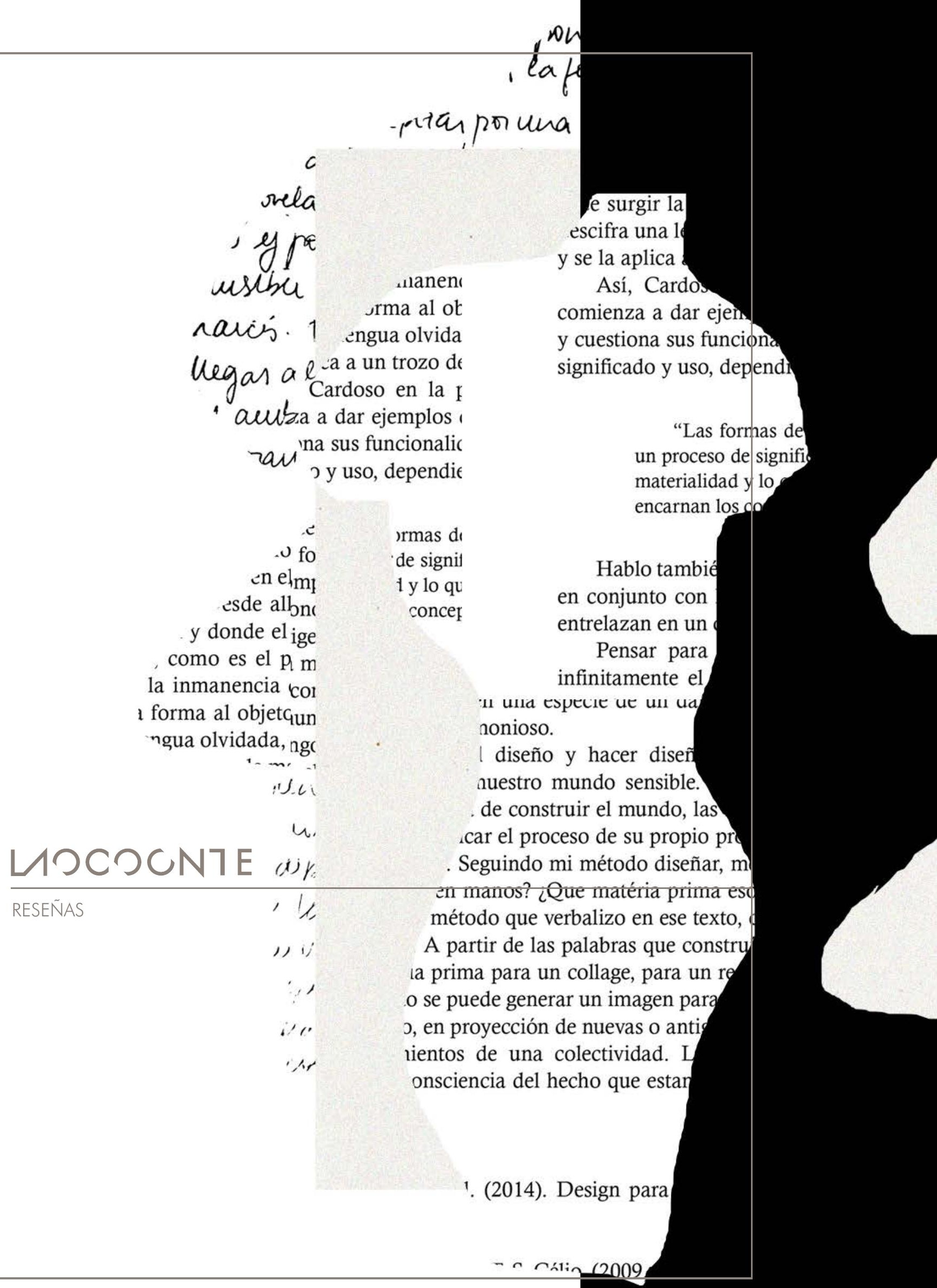




\title{
Estética de la Instalación
}

\author{
Luis Cemillán Casis*
}

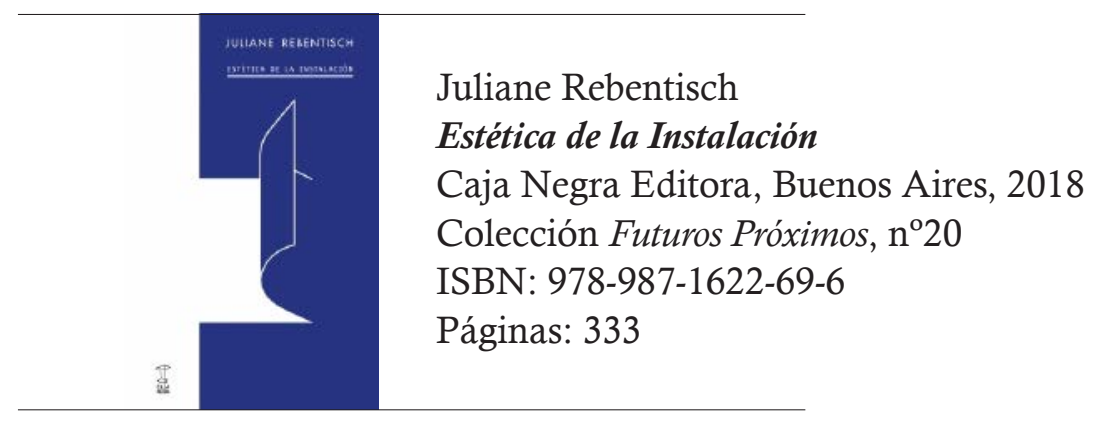

La editorial Caja Negra es la primera que se ha aventurado a publicar en español una de las obras imprescindibles de Juliane Rebentisch, profesora de Filosofía y Estética en la HfG Offenbach y presidenta de la Deutsche Gesellschaft für Ästhetik. Si bien numerosas y heterogéneas han sido las aproximaciones hacia la instalación artística desde que la crítica de arte de los 60 en adelante conceptualizara la posibilidad de un(as) arte(s) expandido(as), este volumen supone, en sí mismo, una expansión desde el propio acercamiento teórico a estas prácticas, al partir la autora desde el ámbito de la estética filosófica. Y es que Estética de la Instalación advierte de que hay que superar la literatura de confrontación que se ha practicado hasta el momento entre el academicismo y el plano de la crítica y prácticas artísticas, ya que se han dedicado a trazar un camino cada vez más irreconciliable entre ambas. Frente a esta disputa, la novedad que se propone con el presente volumen, y pese a que, como advierte la propia autora, el título pueda llevar a confusión, no pasa por tratar de demarcar las peculiaridades de una posible instalación como género artístico, ni tampoco por elaborar una especie de clasificación en base a ejemplos y prototipos concretos. Más bien, bajo un acercamiento desde la metodología de la estética filosófica, Rebentisch se propone defender la capacidad con la que la instalación ha permitido cuestionar y repensar alguno de los problemas esenciales para la teoría del arte (hasta entonces leídos sólo desde la crítica modernista y no tanto desde la filosofía), como son la autonomía de la obra, las posiciones y relación entre sujeto y objeto, lo orgánico e inorgánico... En este sentido, si bien asegura que desde la crítica defensora del modernismo se rechazó en un principio el arte instalativo por su falta (aparente) de autonomía, y que la crítica posmoderna, afín a la instalación, rechazaba de por sí el concepto de autonomía estética, la tesis fundamental de Rebentisch es que al "actualizar, reunir y agudizar problemas centrales del discurso estético moderno” (p.18), una posible defensa de la autonomía por parte del arte instalativo ya no tendría cabida en los estándares o debates del modernismo estético. Así, no se trataría entonces de pensar que la instalación se opone a la autonomía artística, sino que las prácticas instalativas establecen y reformulan un 
"nuevo encuadre" o una nueva forma de pensar su autonomía estética, más allá de la defendida por el discurso objetivista moderno. Y este nuevo encuadre es el que trata de dibujar a través de un complejo volumen (dividido en tres capítulos encabezados por tres problemas propios de la estética), en el que obliga a conversar a múltiples autores tan dispares como Theodor Adorno, Martin Heidegger o Rosalind Krauss, entre otros.

En el primer capítulo, Rebentisch parte de la crítica puramente teatral al reconocer cómo uno de los conceptos clave del arte instalativo es el de la teatralidad, por lo que decide retrotraerse a la crítica a este concepto que protagonizó en los años 60 Stanley Cavell y su traslación a la práctica minimalista por el crítico Michael Fried. Los trabajos de estos críticos atacan directamente al concepto de teatralidad (o al de estetización) al considerar que la separación clásica entre escenario y la sala de espectadores oscura produce una cosificación amoral que distancia al espectador con el mundo y lo sitúa en una relación puramente voyeurística, de compasión y apropiación. Lo que aplicado por Fried para el arte minimalista tiene que ver con la forma con la que la "inclusión" o dependencia del observador y la "literalidad" latentes en las obras minimalistas niegan la "presentidad" en la que se apoya la autonomía del arte: "los materiales no representan ni significan ni aluden a nada: son lo que son y nada más" (57). Como para la crítica modernista el arte debe trascender su objetualidad a través de la forma, para ambos críticos la autonomía de la obra requiere de la prevalencia del objeto estético frente al sujeto observador, al que no se le permite más que reconocer su condición de testigo. No obstante, Rebentisch va a proponer un sentido diferente para el concepto de teatralidad, de tal forma que llega a afirmar que la teatralidad no es una característica propia y por tanto criticable de las obras de instalación, sino que es un rasgo estructural de todo el arte, en tanto que todo objeto estético tiene una presencia escénica doble, como cosa y como signo. Como consecuencia, Rebentisch se posiciona frente al objetivismo estético al afirmar no sólo que el problema de la autonomía no se resuelve otorgando una prioridad del objeto frente al sujeto, ni viceversa, sino reconociendo un "acontecer entre" sujeto y objeto, al que llama experiencia estética, que desestabiliza el "acceso comprensivo del sujeto al objeto estético" (43). Es decir, que para ella la teatralidad no establece ninguna jerarquía entre sujeto-objeto sino que reconoce una asimetría tensional y comunicativa que ocurre en ese entre, por la que el objeto siempre se sustrae a toda fijación definitiva de significado y mantiene con el sujeto una relación experimental. Y, sostiene, si bien "la inclusión del espectador" forma parte tanto de la modernidad como de la posmodernidad, lo que las diferencia es que el arte minimalista y de instalación evidencian de una manera más clara este problema de acceso al objeto y desestabilización del sujeto (que ahora es performativo, corpóreo y móvil), problema que en realidad siempre ha sido insalvable también para la obra moderna. Es decir, para ella el malentendido objetivista sobre la autonomía del arte se supera al entender a la autonomía como experiencia estética; es decir, al asumir que "el arte es autónomo, no a pesar sino a causa de la inagotabilidad de la experiencia" (70).

En el extensísimo segundo capítulo, Rebentisch se detiene sobre cómo el concepto de intermedialidad ha afectado a las modernas clasificaciones de las artes (convencionalmente encasilladas en géneros y categorías) y para el que ha existido un profundo rechazo desde los críticos objetivistas. En primer lugar, la autora comienza recogiendo las aportaciones de aquellos que piensan que la intermedialidad de las artes rechaza a su autonomía, bien porque crean que la autonomía tiene que ver con los recursos o medios específicos de representación (como Clement Greenberg), o porque se rechace 
la incursión de la "espectacularidad" en la industria cultural (Krauss) o porque se defienda que la especificidad del medio entronca directamente con la del género (Fried). No obstante, más allá de identificar la autonomía artística con la especificidad o reafirmación de una posible identidad de cada género, Juliane sigue las tesis de Luhmann para quien la obra de arte es ante todo un "medio social". De esta manera, afirma que la autonomía estética no es algo que dependa de la producción (previa) de la obra ni algo que tenga que ver con un "área de competencia única del artista", sino que la obra existe imprescindiblemente en el proceso de su observación, de su sustracción: "en el proceso de una experiencia de relación de objeto específicamente estética" (111). En este sentido, la intermedialidad no se enfrentaría a la autonomía sino que sería parte de su definición. Y esto es posible porque para ella la autonomía de la obra leída en clave de experiencia estética exige entender el medio artístico no como un recurso de representación específico de cada arte, sino como un llamado a interrelacionarse infinitamente: "el horizonte potencialmente infinito y abierto de las posibles formaciones de interrelación" (109). Cualquier otro intento de identificar la autonomía del arte con su medio específico o habilidad artística no es más que un intento de objetivación en el discurso público; una impresión de orden y unidad. Además, ella llega a demostrar cómo ha sido la crisis propiciada por la intermedialidad la que precisamente ha permitido la reflexión sobre las cualidades específicas de los distintos medios, y no al revés. En segundo y último lugar, Rebentisch aterriza en algunos casos concretos de obras intermediales (instalaciones teatrales, cinematográficas y sonoras) para demostrar cómo estas prácticas no desechan la idea de autonomía estética ni se alejan de la reflexión de los medios concretos, sino que los radicalizan y complejizan.

Por último, en el que supone el capítulo más corto y, quizás por ello, de precipitado cierre, la autora se refiere, con especificidad de sitio, a la doble reflexión sobre el espacio que tematizan la mayor parte de las obras de instalación: el lugar literal de exhibición y la dimensión social en las que se inscriben. Siendo altamente "políticas" (y "politizadas") estas obras, la propia crítica posmoderna ha creído conveniente rechazar la idea de arte autónomo modernista, por creerla apolítica y poco comprometida. No obstante, lo que va a replantear Rebentisch, una vez más, es que ese rechazo sólo se produce si entendemos autonomía según la concepción objetivista en este libro superada. Si, en cambio, nos situamos según la teoría de la experiencia que propone la autora, la simple y vaga referencia semántica al contexto social de las obras instalativas resulta insuficiente para reflexionar sobre su lugar doble. Más que rechazar la autonomía del arte, los trabajos con especificidad de sitio reflexionan, precisamente, en el modo en el que se produce su esteticidad. Entonces, a partir de una relectura de la relación arte-espacio en Heidegger, Rebentisch plantea que algunas instalaciones permiten una experiencia estética en la que se reflexiona sobre el encuadre institucional, social, económico y político al "intervenir formalmente" en una arquitectura dada. De esta manera, la reflexividad del contexto no es contraria a su autonomía, sino un aspecto esencial o fundacional de su definición: los lugares y sus límites no son marcados, fundados, hasta que la obra no los "hace lugar", no los funda estéticamente o los hace legibles frente a sí mismos. Para clarificar estas tesis, Rebentisch termina el capítulo refiriéndose a dos etapas de la especificidad de sitio: las prácticas de los años 70 , en las que la pérdida de la neutralidad del cubo blanco y del museo supusieron una forma de reflexionar sobre el lugar doble del arte y hacer explícita la crítica (interna) a las condiciones de mercantilización del mismo; y las de los años 90, en las que el arte 
atacó a la concepción ética y universal de la subjetividad estética anhelada por la "obra total", y empezó a referirse en cambio a contextos sociales concretos, a individuos situados socialmente y a la forma en la que definen de esta manera su acceso estético a la institución. Eso sí, este sujeto siempre se experimentará con el objeto como performativo, autorreflexivo. Si como antes comentaba Juliane la autonomía como experiencia estética debe entenderse como desestabilización de cualquier acceso comprensivo al objeto estético, el arte sólo va a establecer relaciones de significado siempre que se admita su carácter abierto no objetivable. Por tanto, la obra instalativa de especificidad de sitio carece, ante todo, de sitio.

En último término, el trabajo que nos plantea Rebentisch a los lectores y estudiosos del arte a partir de su obra es doble: pensar el motivo por el que estas líneas han tardado quince años en ser traducidas al castellano (como ocurre con muchos otros trabajos que abordan el tema de las artes expandidas); $y$, teniendo en cuenta estas tesis que alteran por completo la noción de autonomía artística, revisar la totalidad de prácticas de instalación en apogeo en estas últimas décadas para ver, de todas ellas, cuáles propician de verdad una experiencia estética autónoma en un sentido antiobjetivista. 


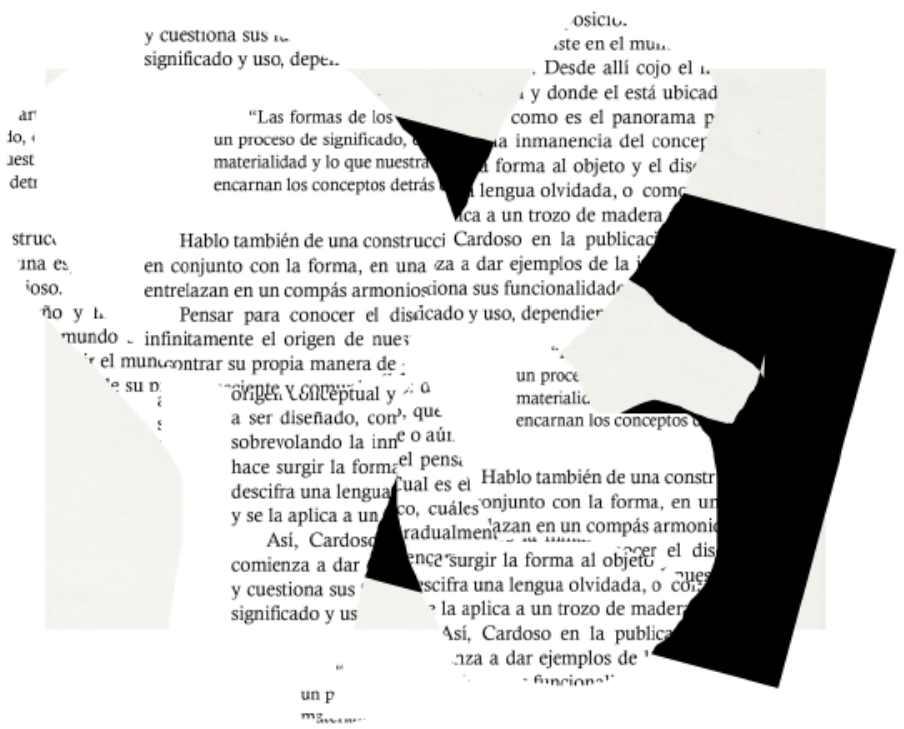

"Lo impreso exige una humildad de espíritu por cuya falta muchas de las bellas artes se tambalean ahora en experimentos de autoconciencia y sensiblería. No hay nada simple ni aburrido en lograr una página transparente. La ostentación vulgar es el doble de fácil que la disciplina".

Beatrice Warde, The Crystal Goblet, or why printings should be invisible (1930)

"El diseño que es objetivo, comprometido con el bien común, bien compuesto y delicado, constituye la base del comportamiento democrático".

Josef Müller-Brockmann, Grid and Design Philosophy (1981) 

EDITA

\section{SEyTA.}

SOCIEDAD ESPAÑLAA
DE ESTETICA Y TEORIA DE LAS ARTES

CON LA COLABORACIÓN DE

\begin{tabular}{|c|c|c|}
\hline 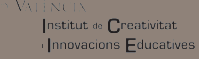 & $\begin{array}{l}\text { VNIVIRSIIA } \\
\text { In VVIIINCI Departament de Filosofia }\end{array}$ & 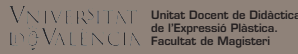 \\
\hline $\begin{array}{l}\text { TitTicA } \\
\text { SoFFA }\end{array}$ & 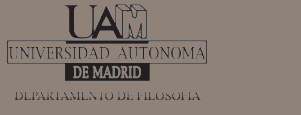 & $\begin{array}{l}\text { UAB } \\
\text { Universitat Autònoma } \\
\text { de Barcelona }\end{array}$ \\
\hline
\end{tabular}

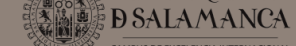

https://ojs.uv.es/index.php/LAOCOONTE/index 